\title{
Synthesis and Characterization of Magnetite and Cobalt Ferrite Nanoparticles by Sol-Gel Auto Combustion Technique
}

\author{
S. D. Raut ${ }^{1}$, S. G. Dahotre ${ }^{2}$, L. N. Singh ${ }^{3}$, S. N.Jadhav ${ }^{4}$ \\ ${ }^{1}$ Research Scholar, ${ }^{2}$ Professor, Head, Department of Physics \\ Dr. Babasaheb Ambedkar Technological University, Lonere, Mangaon, Raigad, India, 402103,
}

\begin{abstract}
Magnetite and Cobalt ferrite nanoparticles were prepared by sol-gel auto combustion technique. This method is very simple and easy to achieve magnetite and cobalt ferrite nanoparticles in powder form. The nanocrystalline forms of synthesized sample were obtained at very low annealing temperature of about $600^{\circ} \mathrm{C}$. From $X R D$, it reveals that cobalt ferrite nanoparticles are highly crystalline in nature and average crystallite size obtained is almost 30nm. SEM image shows the cubic spinel form of synthesized sample. Vibrating sample magnetometer is used to study the magnetic properties which shows that the saturation magnetization of cobalt ferrite is higher than saturation magnetization of magnetite nanoparticles, also anisotropic constant of cobalt ferrite nanoparticles is higher than magnetite nanoparticles, confirms the single domain of sample which is also verified by squareness ratio. It is observed from FTIR characterization that, the metal-oxide bonds like $\mathrm{Fe}-\mathrm{O}$ and $\mathrm{Co}-\mathrm{O}$ are present in the sample. The obtained results of cobalt ferrite nanoparticles are having more advantageous than magnetite nanoparticles for the applications of MRI and magnetic sensors.
\end{abstract}

Keywords- Magnetite, Cobalt ferrite, Magnetic properties, sol-gel auto combustion.

\section{INTRODUCTION}

C omplex oxides such as magnetite and cobalt ferrite are very interesting materials. There structural, magnetic, optical and electrical properties help to improve the applications of spintronics devices [1]. In recent years most promising technology is spintronics which introduce to reduce device size, speeding up processing data and store the information in small area [2][3]. In 1988 magnetite is introduced as half metal which gives single spin state either up or down. It gives more advantageous to store the information. This effective magnetic material is applied for spin based devices such as MRI, MRAM, gas sensor [3] [4][5][6]. To improve the magnetic properties for spintronics, here I have studied cobalt doped magnetite. Cobalt ferrite is selected due to high density and high magnetocrystalline anisotropy [7][8]. In this research magnetite $\left(\mathrm{Fe}_{3} \mathrm{O}_{4}\right)$ is replace by cobalt ferrite $\left(\mathrm{CoFe}_{2} \mathrm{O}_{4}\right)$. Comparative study has been done for the study of structural and magnetic properties of magnetite and cobalt ferrite.

Different methods have been used to synthesis magnetite and cobalt ferrite such as co-precipitation, mechanochemical, thermal hydrolysis, sol-gel, sol-gel auto combustion[9][10][11][12][13]. Among various methods sol gel auto combustion is very simple and require less time for synthesis of sample.

\section{LITERATURE REVIEW}

V.R. bhagwat et. al., reported the synthesis of cobalt ferrite carried out by sol-gel auto combustion method 


\section{International Journal of Innovations in Engineering and Science, www.ijies.net}

using three different fuels such as ethylene glycol, urea and glycine. From XRD crystalline size obtained in the range of 22.10 to $15.11 \mathrm{~nm}$. It has been also observed that, saturation magnetization, remenant magnetization and coercivity inceases with the increase in size of the the nanoparticles[14].

Thapa et. al. and co-workers reported in research work the crystalline size calculated is below $10 \mathrm{~nm}$ due to which surface effects cause saturation magnetization decreases and hence magnetite materials changes from ferromagnetic to superparamagnetic in nature which is used for flexible spintronics devices[15].

Hassan Soleimani, et. al., studied the cobalt substituted magnetite by co-precipitation method. The crystalline size calculated in the range $13 \mathrm{~nm}$ to $35 \mathrm{~nm}$ with increase in $\mathrm{Co}^{2+}$ ions concentration from XRD. It also observed the FTIR analysis of cobalt substituted magnetite which gives qualitative study of the ions at tetrahedral and octahedral sites was observed at wavenumbers ranging from 600 to $400 \mathrm{~cm}^{-1}$. It has been observed from FTIR, presence of metal oxygen bond in the cobalt substitute magnetite [16].

\section{METHODOLOGY}

\section{Chemicals}

All Iron nitrate, cobalt Nitrate, deionized water, citric acid (AR grade), $\left[\mathrm{NH}_{4} \mathrm{OH}\right]$ ammonia solution to maintain $\mathrm{pH}$ were purchased from Merck and used without further purification.

\section{Synthesis Method}

Iron nitrate, cobalt nitrate and citric acid were used for the preparation of cobalt ferrite are of AR grade. A known quantity of Iron nitrate and cobalt nitrate was dissolved in deionized water and mixed with citric acid as 1:1 molar ratio. To maintain the $\mathrm{pH} 7$, add ammonia solution drop wise. This solution was stirred for 2 hours and then a sol gets formed. The solution was then heated to $90^{\circ} \mathrm{C}$ for 2 hours to form a brownish gel. This gel was decomposed at same temperature in oven. The gel then converted into fluffy powder consists of homogeneous flakes of very small particle size shown in Fig. 1. This powder was crushed by using mortar and pestle and placed for annealing in muffle furnace at temperature $600^{\circ} \mathrm{C}$ gives fine powder of sample for characterization of XRD, FESEM, VSM and FTIR.

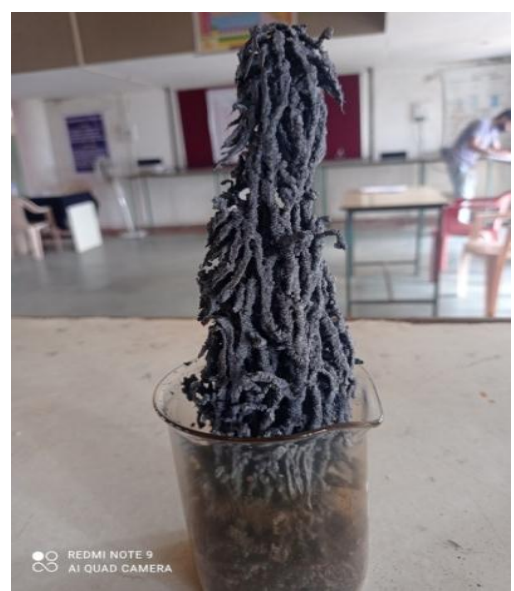

Fig.1 - Synthesized fluffy powder of cobalt ferrite

\section{RESULT \& DISCUSSION}

\section{Characterizations}

The nanoparticles were characterized with the help of XRD, FESEM, VSM and FTIR. The XRD measurement carried out using $\mathrm{Cu}-\mathrm{K} \alpha$ radiation. FESEM image carried out for study of surface morphology. VSM characterization gives information regarding magnetic properties at room temperature and FTIR spectra recorded in the range of $4000 \mathrm{~cm}^{-1}$ to 400 $\mathrm{cm}^{-1}$.

\section{$X$-ray Diffraction (XRD)study}

Fig. 2 shows the XRD peaks which gives crystalline nature of magnetite and cobalt ferrite. The various peaks of magnetite at $30.30^{\circ}, 35.65^{\circ}, 43.56^{\circ}, 54.08^{\circ}, 57.59^{\circ}$ and $62.99^{\circ}$ are obtained and in cobalt ferrite various peaks obtained at $30.20^{\circ}, 35.54^{\circ}, 43.19^{\circ}, 53.56^{\circ}$, $57.09^{\circ}$ and $62.76^{\circ}$. It reveals that the minor shift in peak position may happen due to ionic radius of $\mathrm{Co}^{2+}$ which is slightly greater than $\mathrm{Fe}^{2+}$ ion[17] [18].

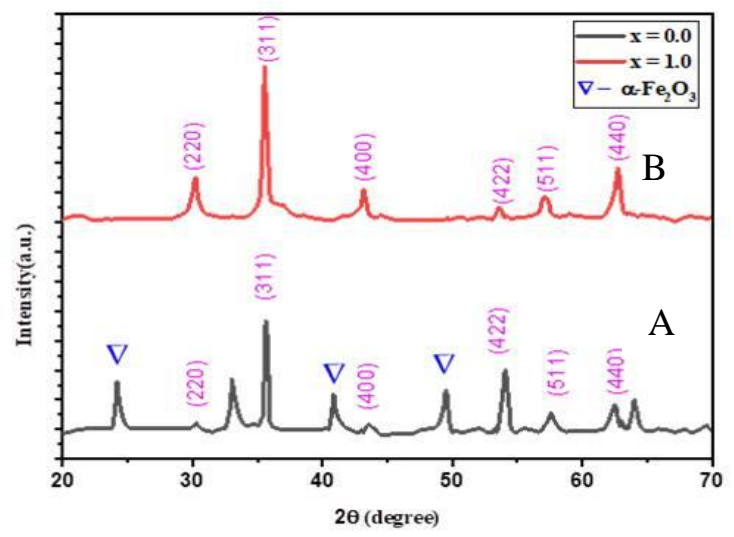

Fig.2 - XRD graph of magnetite and cobalt ferrite. 


\section{International Journal of Innovations in Engineering and Science, www.ijies.net}

The XRD pattern of magnetite peak (A) shows that minor impurity of hematite $\left(\alpha-\mathrm{Fe}_{2} \mathrm{O}_{3}\right)$ is present in sample and strong reflection of peaks are obtained at (220), (311), (400), (422), (511) and (440). From peak (B) it has been observed that no additional impurity is present. From the XRD graph both peak shows the FCC type of spinel structure[14].

We have calculated various parameters as lattice constant (a), x-ray density, volume of unit cell, hopping length at tetrahedral site (LA), hopping length at octahedral site (LB), and crystallite size from XRD graphs which are shown in Table 1.

Table 1: Various parameters of magnetite and cobalt ferrite

\begin{tabular}{|l|l|l|}
\hline Parameters & $\begin{array}{l}\text { Magnetite } \\
\text { (Average) }\end{array}$ & $\begin{array}{l}\text { Cobalt } \\
\text { ferrite } \\
\text { (Average) }\end{array}$ \\
\hline Lattice constant (a) & $8.3334 \AA$ & $8.3749 \AA$ \\
\hline Crystallite size( $\mathrm{D})$ & $34.02 \mathrm{~nm}$ & $30.8 \mathrm{~nm}$ \\
\hline $\begin{array}{l}\mathrm{X}-\mathrm{ray} \text { density ( }(\rho) \\
(\mathrm{g} / \mathrm{cc})\end{array}$ & 5.31355 & 5.307141 \\
\hline Unit cell volume $(\mathrm{V})$ & $578.7642 \AA^{3}$ & $\begin{array}{l}587.4145 \\
\AA^{3}\end{array}$ \\
\hline Hopping length $\left(\mathrm{L}_{\mathrm{A}}\right)$ & $3.608 \AA$ & $3.626 \AA$ \\
\hline Hopping length $\left(\mathrm{L}_{\mathrm{B}}\right)$ & $2.946 \AA$ & $2.960 \AA$ \\
\hline
\end{tabular}

The average crystalline size (D) was calculated by using the Scherrer's formulae.

$$
D=\frac{K \lambda}{\beta \sin \theta}
$$

Where, $\mathrm{K}$ is crystallite constant (0.94), $\lambda$ is wavelength, $\beta$ is FWHM and $\theta$ is peak position.

From the above Table 1 it is observed that crystallite size of magnetite is $34.02 \mathrm{~nm}$ whereas for cobalt ferrite it is $30.8 \mathrm{~nm}$. From this we conclude that when we add cobalt in pure magnetite, crystallite size decreases due to minor shift in peak position of synthesized sample which confirms that, crystallite size is dependent on $\mathrm{M}^{2+}$ ion . The hopping length is the distance between magnetic ions in the given sample. In pure magnetite and cobalt ferrite, tetrahedral and octahedral sites are present due to which lattice constant influences on hopping length [19]. From above, it concludes that the hopping length varies due to doping of cobalt in pure magnetite.

\section{Field Emission Scanning Electron Microscopy (FESEM)}

Fig. 3 and Fig.4 shows the FESEM images of magnetite and cobalt ferrite, which consist of random distribution of agglomerated particles originated from the eruption of fuels during synthesis process.

The sponge like morphology is observed in cobalt ferrite sample.

\section{Vibrating Sample Magnetometer(VSM)}

The magnetic properties of magnetite and cobalt ferrite samples were recorded by using VSM at room temperature with applied field ranging upto $1500 \mathrm{Oe}$ is shown in Fig.5 and Fig.6. The magnetic hysteresis loop confirms that the sample shows ferromagnetic performance with soft and hard magnetic nature of magnetite and cobalt ferrite sample [14].

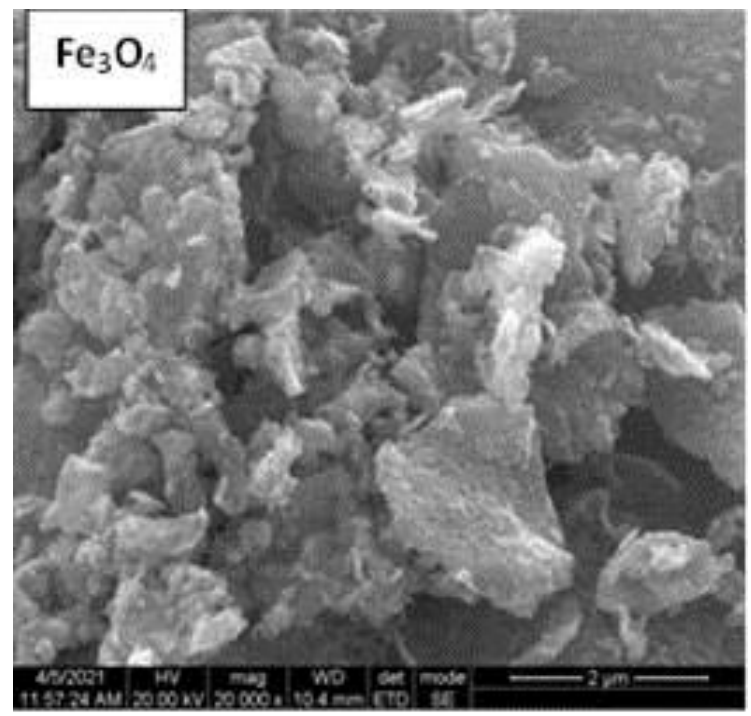

Fig.3 -FESEM image of magnetite sample

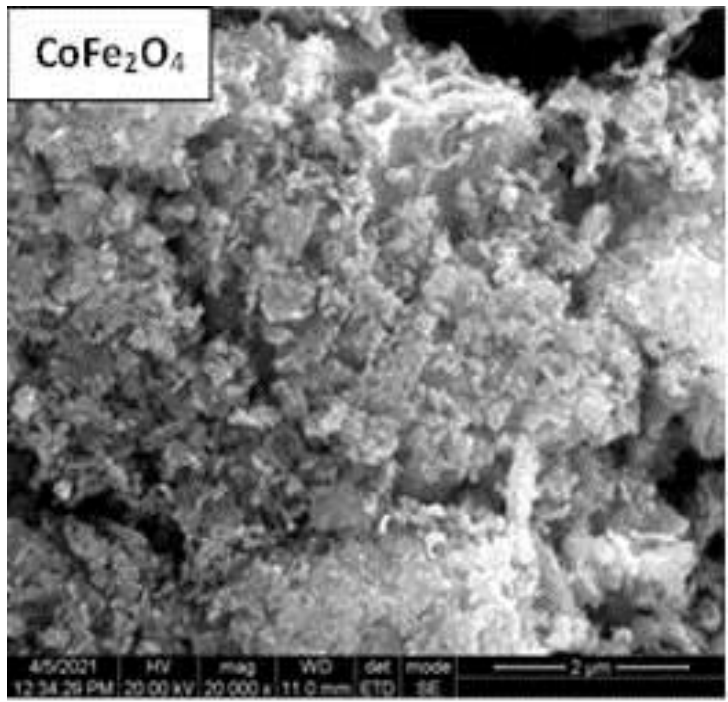

Fig.4 - FESEM image of Cobalt ferrite

Coercivity $\left(\mathrm{H}_{\mathrm{C}}\right)$, remanence magnetization $\left(\mathrm{M}_{\mathrm{r}}\right)$, saturation magnetization $\left(\mathrm{M}_{\mathrm{S}}\right)$ and magnetic crystalline 
Vol. 6, No. 10, 2021, PP. 17-22

\section{International Journal of Innovations in Engineering and Science, www.ijies.net}

anisotropy $(\mathrm{K})$ values are summarized in Table 2.

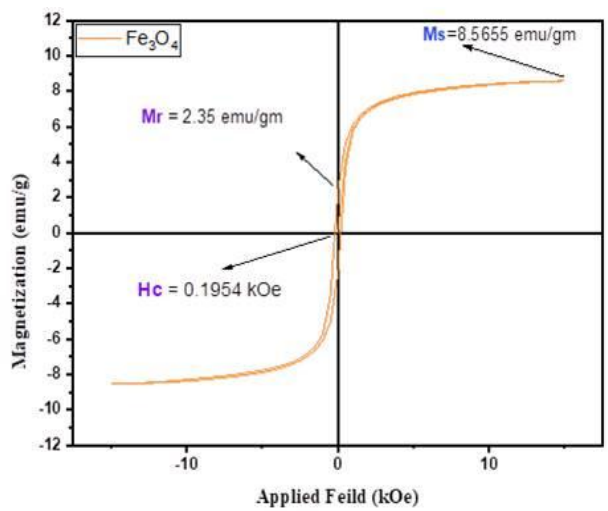

Fig.5 - VSM graph of pure magnetite

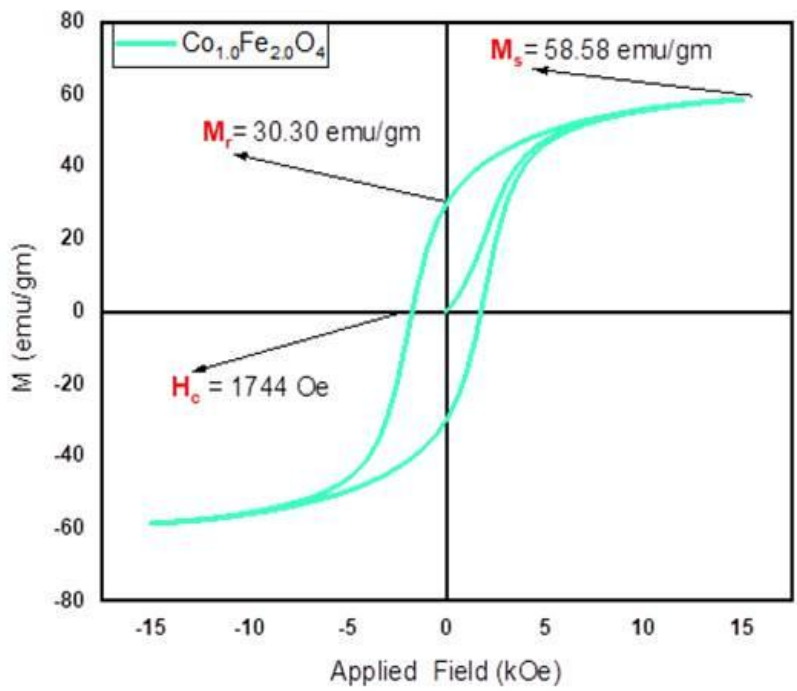

Fig.6 - VSM graph of cobalt ferrite

Table 2-Various parameters of magnetic material

\begin{tabular}{|l|l|l|}
\hline Parameters & Magentite & Cobalt ferrite \\
\hline Coercivity (Hc) & $195.4 \mathrm{Oe}$ & $1744 \mathrm{Oe}$ \\
\hline $\begin{array}{l}\text { Saturation } \\
\text { magnetization (Ms) }\end{array}$ & $8.565 \mathrm{emu} / \mathrm{g}$ & $58.58 \mathrm{emu} / \mathrm{g}$ \\
\hline $\begin{array}{l}\text { Remenance } \\
\text { Magnetization (Mr) }\end{array}$ & $2.35 \mathrm{emu} / \mathrm{g}$ & $30.30 \mathrm{emu} / \mathrm{g}$ \\
\hline $\begin{array}{l}\text { Squarenes ratio } \\
\text { (Mr/Ms) }\end{array}$ & 0.27 & 0.51 \\
\hline $\begin{array}{l}\text { Magnetocrystalline } \\
\text { anisotropy (K) }\end{array}$ & $\begin{array}{l}1743.43615 \\
\mathrm{erg} / \mathrm{g}\end{array}$ & $\begin{array}{l}106420.333 \\
\mathrm{erg} / \mathrm{g}\end{array}$ \\
\hline \multicolumn{2}{|l}{}
\end{tabular}

From Table 2, it concludes that saturation magnetization increases due to $\mathrm{Co}^{2+}$ ions. It may happen as ionic radii of $\mathrm{Co}^{2+}$ ions greater than $\mathrm{Fe}^{2+}$ ions. Since squareness ratio of cobalt ferrite is around 0.5 which indicates the single domain nature of the sample [20][21]. The Magnetocrystalline anisotropy $(\mathrm{K})$ is also high which is potential applications of spintronics.

\section{Fourier Transformer Infra-Red Spectroscopy (FTIR)}

The Fourier Transform Infra-red spectroscopy recorded for the synthesized sample of magnetite and cobalt ferrite shows the presence of metal oxygen bond. The various frequencies obtained are as shown in Table 3.

Table 3- FTIR data of magnetite and cobalt ferrite

\begin{tabular}{|l|l|l|l|l|}
\hline sample & $\overline{\mathbf{v}}_{\mathbf{1}}$ & $\overline{\mathbf{v}}_{\mathbf{2}}$ & $\overline{\mathbf{v}}_{\mathbf{3}}$ & $\overline{\mathbf{v}}_{\mathbf{4}}$ \\
\hline $\begin{array}{l}\text { Pure } \\
\text { magnetite }\end{array}$ & 3444.1 & 1635.37 & 549.71 & 470.63 \\
\hline $\begin{array}{l}\text { Cobalt } \\
\text { ferrite }\end{array}$ & 3429.4 & 1635.6 & 580.57 & 412.77 \\
\hline
\end{tabular}

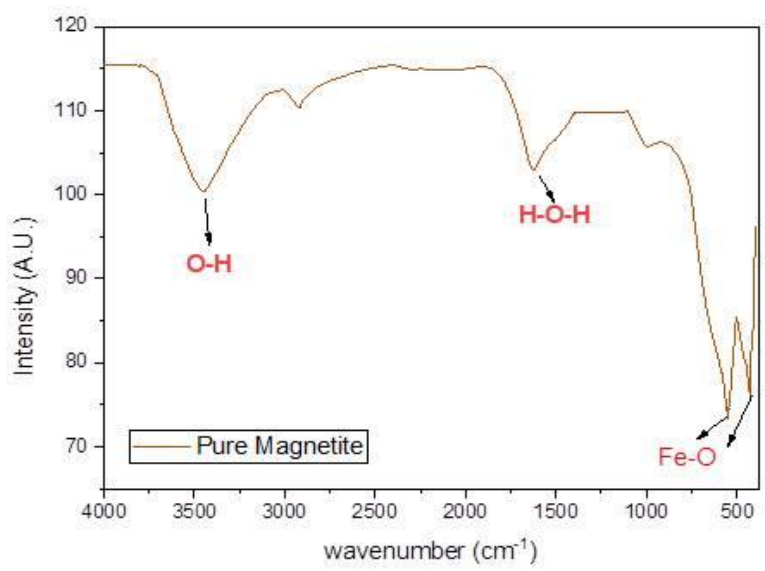

Fig.7 - FTIR spectrum of magnetite

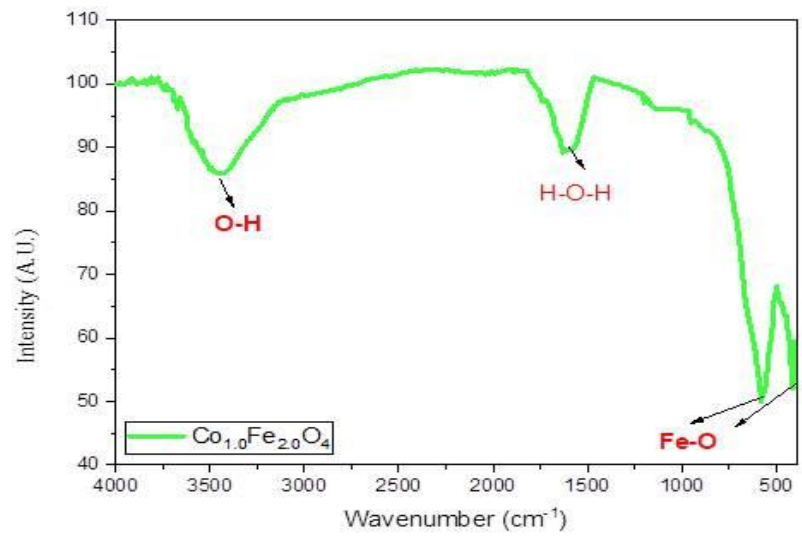

Fig. 8- FTIR spectrum of cobalt ferrite

The Fig. 7 and Fig. 8 shows the FTIR graph of pure magnetite and cobalt ferrite which helps to show various bonds present in synthesized sample. $\bar{v} 1=3444.1 \mathrm{~cm}-1$, $3429.4 \mathrm{~cm}^{-1}$ indicates the $\mathrm{O}-\mathrm{H}$ bond in the functional group region. $\bar{v} 2=1635.37 \mathrm{~cm}^{-1}, 1635.6 \mathrm{~cm}^{-1}$ indicates the presence of $\mathrm{H}-\mathrm{O}-\mathrm{H}$ bond due to deionized water which is 


\section{International Journal of Innovations in Engineering and Science, www.ijies.net}

used at the time of synthesis process [16]. $\bar{v}_{3}$ and $\bar{v}_{4}$ shows the $\mathrm{Fe}^{3+}-\mathrm{O}$ bond at tetrahedral site and $\mathrm{Fe}^{2+}-\mathrm{O}$ at octahedral site respectively. It shows maximum absorption of infrared light due to metal and non-metal ion bonding.

\section{CONCLUSION}

Synthesis of pure magnetite and cobalt substituted magnetite is successfully carried out with sol-gel auto combustion method. Synthesized cobalt substituted magnetite is in the nanoscale range. Pure magnetite has slightly larger crystallite size than cobalt ferrite. The FESEM image shows the morphology of magnetite and cobalt ferrite and confirms spinel structure of sample. From VSM graph it concludes that, coercivity, saturation magnetization and magnetocrystalline anisotropy of cobalt ferrite is greater than that of pure magnetite which is potential applications of MRI, gas sensor, MRAM. From FTIR it is observed that metal-oxide (M-O) bond is present in the range of $580 \mathrm{~cm}^{-1}$ to $400 \mathrm{~cm}^{-1}$. Due to higher intensity of peaks of cobalt ferrite, stretching and vibrations of $\mathrm{Co}-\mathrm{O}$ bond is greater than that of $\mathrm{Fe}-\mathrm{O}$ bond. Finally, it has been concluded that, cobalt doped magnetite is more effective than the pure magnetite.

\section{ACKNOWLEDGMENT}

Authors are thankful to the Dr. Sandesh Jaybhaye for XRD characterization facility. The authors also thankful to acknowledge SAIF, IIT madras for providing characterization facilities

\section{REFERENCES}

[1] R. K. Kotnala and J. Shah, Ferrite Materials: Nano toSpintronics Regime, vol. 23. Elsevier, 2015.

[2] S. Mesoraca, S. Knudde, D. C. Leitao, S. Cardoso, and M. G. Blamire, "All-spinel oxide Josephson junctions for high-efficiency spin filtering," 2018.

[3] S. Bhatti, R. Sbiaa, A. Hirohata, H. Ohno, S. Fukami, and S. N. Piramanayagam, "Spintronics based random access memory: a review," Mater. Today, vol. 20, no. 9, pp. 530-548, 2017, doi: 10.1016/j.mattod.2017.07.007.

[4] T. A. Lastovina et al., "Solvothermal synthesis of Sm3 +doped Fe3O4 nanoparticles," Mater. Sci. Eng. C, vol. 80, pp. 110-116, 2017, doi: 10.1016/j.msec.2017.05.087.

[5] N. M. Caffrey, D. Fritsch, T. Archer, S. Sanvito, and C. Ederer, "Spin-filtering efficiency of ferrimagnetic spinels CoFe $2 \mathrm{O} 4$ and NiFe $2 \mathrm{O}$ 4," pp. 1-8, 2013.

[6] W. Liu, P. K. J. Wong, and Y. Xu, "Hybrid spintronic materials: Growth, structure and properties," Prog. Mater. Sci., vol. 99, no. February 2018, pp. 27-105, 2019, doi: 10.1016/j.pmatsci.2018.08.001.

[7] B. J. Rani, M. Ravina, B. Saravanakumar, G. Ravi, V. Ganesh, and S. Ravichandran, "Nano-Structures \& Nano-Objects Ferrimagnetism in cobalt ferrite ( $\mathrm{CoFe} 2$ O 4 ) nanoparticles," vol. 14, pp. 84-91, 2018, doi: 10.1016/j.nanoso.2018.01.012.
[8] N. M. Caffrey, D. Fritsch, T. Archer, S. Sanvito, and C. Ederer, "Spin-filtering efficiency of ferrimagnetic spinels CoFe2O 4 and NiFe2O4," Phys. Rev. B - Condens. Matter Mater. Phys., vol. 87, no. 2, pp. 1-7, 2013, doi: 10.1103/PhysRevB.87.024419.

[9] D. A. Rayan, M. A. Zayed, and G. M. A. Al Maqsoud, "Structure, Optical, and Magnetic Properties of Magnetite Nanoparticles Doped with Zinc and Lanthanum and Prepared in Oxygen and Nitrogen Atmosphere," vol. 2, pp. 1-11, 2019, doi: 10.32371/jtmc/236083.

[10] B. Kalska-Szostko, U. Wykowska, D. Satula, and P. Nordblad, "Thermal treatment of magnetite nanoparticles," Beilstein J. Nanotechnol., vol. 6, no. 1, pp. 1385-1396, 2015, doi: 10.3762/bjnano.6.143.

[11] T. Iwasaki et al., "Mechanochemical preparation of magnetite nanoparticles by coprecipitation," Mater. Lett., vol. 62, no. 25, pp. 4155-4157, 2008, doi: 10.1016/j.matlet.2008.06.034.

[12] A. B. Shinde, "Structural and Electrical Properties of Cobalt Ferrite Nanoparticles," no. 4, pp. 64-67, 2021.

[13] R. S. Yadav et al., "Structural, Cation Distribution, and Magnetic Properties of CoFe 2 O 4 Spinel Ferrite Nanoparticles Synthesized Using a Starch-Assisted SolGel Auto-Combustion Method," J. Supercond. Nov. Magn., vol. 28, no. 6, pp. 1851-1861, 2015, doi: 10.1007/s10948-015-2990-0.

[14] V. Bhagwat, A. Humbe, ... S. M.-M. S. and, and undefined 2019, "Sol-gel auto combustion synthesis and characterizations of cobalt ferrite nanoparticles: different fuels approach," Elsevier, Accessed: Jul. 08, 2021. [Online]. Available: https://www.sciencedirect.com/science/article/pii/S09215 10719301916.

[15] D. Thapa, V. R. Palkar, M. B. Kurup, and S. K. Malik, "Properties of magnetite nanoparticles synthesized through a novel chemical route," Mateerials Lett., vol. 58, pp. 2692-2694, 2004, doi: 10.1016/j.matlet.2004.03.045.

[16] H. Soleimani, N. R. A. Latiff, H. M. Zaid, N. Yahya, A. R. Sadrolhosseini, and M. Adil, "Influence of cobalt substitution on the structural and magnetic properties of cobalt substituted magnetite," AIP Conf. Proc., vol. 1787, 2016, doi: 10.1063/1.4968106.

[17] S. Kanagesan, ... M. H.-D. J. of, and undefined 2013, "SOL-GEL AUTO-COMBUSTION SYNTHESIS OF COBALT FERRITE AND IT'S CYTOTOXICITY PROPERTIES.," search.ebscohost.com, vol. 20, no. 4, pp. 1601-1610, 2013, Accessed: Jul. 08, 2021. [Online]. Available:

http://search.ebscohost.com/login.aspx?direct=true \&prof ile $=$ ehost \& scope $=$ site \& authtype $=$ crawler $\& j r n l=184235$ $82 \& A N=97593330 \& h=3 Y 42 e 3 o T W z D E q t m \% 2 B I 17 r Z E$ USdXC7OtzY7YDHxciphePxIu7PTZ9yXYzHb4NPzchdFV I7IbU\%2Bk8tsiqH6mtKGUQ\%3D\%3D\&crl=c.

[18] V. P. Senthil, J. Gajendiran, S. G. Raj, T. Shanmugavel, G. Ramesh Kumar, and C. Parthasaradhi Reddy, "Study of structural and magnetic properties of cobalt ferrite (CoFe2O4) nanostructures," Chem. Phys. Lett., vol. 695, pp. 19-23, Mar. 2018, doi: 10.1016/j.cplett.2018.01.057.

[19] S. Anjum and A. Masud, "Structural and temperature dependent dielectric properties of tin substituted cobalt ferrites (SnxCo1-xFe2O4)," Dig. J. Nanomater. Biostructures, vol. 13, no. 4, pp. 1063-1080, 2018.

[20] L. Kumar, P. Kumar, A. Narayan, and M. Kar, "Rietveld analysis of XRD patterns of different sizes of 
Vol. 6, No. 10, 2021, PP. 17-22

International Journal of Innovations in Engineering and Science, www.ijies.net

nanocrystalline cobalt ferrite," Int. Nano Lett., vol. 3, no. 1, 2013, doi: 10.1186/2228-5326-3-8.

[21] R. S. S. Aravazhi, C. Selva, and S. Senthil, "Tuning of ferrites - ( $\mathrm{Co} x \mathrm{Fe} 3$ - $x \mathrm{O} 4)$ nanoparticles by co precipitation technique," SN Appl. Sci., vol. 1, no. 3, pp. 1-11, 2019, doi: 10.1007/s42452-019-0244-7. 